\title{
AVALIAÇÃO DA DEMANDA ENERGÉTICA DE UM DESINTEGRADOR-PICADOR-MOEDOR (DPM) NA MOAGEM DE MILHO
}

Luiz Henrique de Souza ${ }^{1}$, Gutemberg Pereira Dias², Luiz César Vieira de Souza ${ }^{3}$, Ingrid Gomes Dias ${ }^{4}$, Denílson Eduardo Rodrigues ${ }^{5}$

\section{RESUMO}

O objetivo deste trabalho foi avaliar a demanda energética de um desintegrador-picador-moedor, na moagem de milho, submetido a quatro rotações $(4000,3757,2931$ e $2335 \mathrm{rpm})$, quatro número de martelos (4, 5, 6 e 7) e três tipos de peneiras ( 3,5 e $10 \mathrm{~mm}$ de diâmetro dos furos). Os resultados mostraram que tanto a capacidade de produção como o consumo específico foram influenciados pelo número de martelos. A peneira de $3 \mathrm{~mm}$ foi a que demandou maior potência. Há a necessidade de estudos de diferentes modificações no projeto da máquina, que permitam demonstrar sua influência na diminuição do consumo específico de energia. A utilização da peneira de maior diâmetro torna- se uma opção na moagem do milho para diminuição da demanda energética. Para a capacidade de produção e parao consumo específico de energia foram apresentados os seguintes valores na condição nominal: $0,22 \mathrm{t} \mathrm{h}^{-1} \mathrm{e} 14,9 \mathrm{kWh} \mathrm{t}^{-1}$ na peneira de $3 \mathrm{~mm}$; $0,51 \mathrm{th}^{-1}$ e 7,86 $\mathrm{kWh} \mathrm{t}^{-1}$ na peneira de $5 \mathrm{~mm}$; e $0,48 \mathrm{th}^{-1} \mathrm{e}^{7,03} \mathrm{kWh} \mathrm{t}^{-1}$ na peneira de $10 \mathrm{~mm}$.

Palavras-chave: máquinas agrícolas, consumo específico de energia, eficiência energética

\section{ENERGY DEMAND EVALUATION OF A DISINTEGRATOR/CHOPPER/GRINDER (DPM) IN THE GRINDING CORN}

\begin{abstract}
The aim of this work was to evaluate the hammermill energetic demand, in the corn grinding, submitted to four rotations (4000, 3757, 2931 e $2335 \mathrm{rpm})$, four number of hammer sets (4, 5, 6 e 7) and three sieves hole diameter (3, 5 and 10 $\mathrm{mm}$ ). The results showed that grinding rate, as well as specific energy consumption were influenced by the number of the hammer sets. Specific consumption increased with increasing rotations. In further studies, different design parameters of the hammermills are intended to be altered in order to clearly prove their influence on specific energy consumption success. Sieves with greater hole diameters should preferably be used to diminish the specific energy consumption. In the nominal conditional, grinding rate and specific energy consumption demonstract the following results: $0,22 \mathrm{t} \mathrm{h}^{-1}$ and $14,9 \mathrm{kWh} \mathrm{t}^{-1}$ (sieve $\varphi 3 \mathrm{~mm}$ ); 0,51 t h${ }^{-1}$ and 7,86 $\mathrm{kWh} \mathrm{t}^{-1}$ (sieve $\varphi 5 \mathrm{~mm}$ ) and $0,48 \mathrm{th}^{-1}$ and 7,03 $\mathrm{kWh} \mathrm{t}^{-1}$ (sieve $\varphi 10 \mathrm{~mm}$ ).
\end{abstract}

Keywords: agricultural machines, specific energy consumption, energy efficiency

\section{Recebido para publicação em 12/03/2008. Aprovado em 01/02/2010}

1- Engenheiro Agrícola, D. S., E-mail: 1hesouza@ufmg.br

2- Engenheiro Agrônomo, D.S., E-mail: gpdias@ufv.br

3- Engenheiro Agrônomo, E-mail: lcvsouza@hotmail.com

4- Economia Doméstica, M.S., E-mail: ingridgdias@yahoo.com.br

5- Engenheiro Agrícola, D.S., E-mail: deduardo@ufv.br 


\section{INTRODUÇÃO}

A granulometria do milho, depois de moído, pode variar de muito fina a muito grossa, de acordo com o tamanho dos furos da peneira do moinho. Acreditase que uma das formas possíveis de reduzir custos é por meio da geração de informações mais precisas sobre o grau de moagem do milho, de forma a identificar a granulometria que proporcione o melhor aproveitamento dos nutrientes pelas aves, associado à redução dos gastos com energia elétrica e ao aumento no rendimento de moagem (ZANOTTO et al., 1998).

Um dos principais equipamentos utilizados na moagem do milho éo moinho de martelos, denominado DPM (Desintegrador-Picador-Moedor). Grande parte dessas máquinas é acionada por motores estacionários (elétricos, de combustão interna a óleo diesel ou a gasolina) por intermédio de correias e polias, os quais, no entanto, nem sempre são dimensionados de maneira adequada, resultando, na maioria das vezes, num incremento da demanda energética.

Rodrigues (2000) classifica o DPM como sendo uma máquina composta por martelos montados sobre um eixo girante, um conjunto de peneiras, um ventilador transportador e um ciclone para separação e recepção do produto. Os martelos têm uma separação de 2,5 a 7,5 cm entre si e giram a rotações que variam de 2500 a $4000 \mathrm{rpm}$, dependendo do diâmetro do rotor. Ao redor dos martelos, na parte inferior da máquina, ficam fixas as peneiras, que permitem a passagem dos fragmentos de milho moído. Uma corrente de ar produzida por um sistema de ventilação transporta $o$ farelo até o ciclone, de onde passa para um silo ou um saco, para que seja armazenado. A produção do farelo de milho é atribuída à explosão decorrente do alto impacto com os martelos e ao corte provocado por suas bordas.

Grande parcela dos fabricantes dessas máquinas constitui-se de pequenas fábricas, sem setor de pesquisa e desenvolvimento, nas quais os equipamentos fabricados e comercializados nem sempre funcionam no seu ponto ótimo. Por essa razão, o esforço com vista a induzir a avaliação do desempenho operacional dessas máquinas, a fim de otimizar a eficiência energética, é válido.

No ano de 2001, foi sancionada a lei $\mathrm{n}^{\circ} 10295$, que prevê, em seu artigo $2^{\circ}$, a criação de níveis máximos de consumo específico de energia ou mínimos de eficiência energética, de máquinas e aparelhos e que define a relação de equipamentos que devem atender aos requisitos mínimos de eficiência (MINISTÉRIO
DE MINAS E ENERGIA, 2002). A lei incluiu entre eles o DPM.

Muitos autores, que trabalharam com desempenho de equipamentos eletrorrurais, concluíram que a rotação que fornecia melhor demanda energética nem sempre era aquela recomendada pelo fabricante. É o caso de Pereira et al. (2000) e Rodrigues (2000), que trabalharam com o desempenho de picadoras e ensiladoras de forragem e com o desempenho de Desintegradores-Picadores-Moedores na moagem do milho, respectivamente.

Rodrigues (2000) trabalhou com cinco diferentes marcas comerciais desse tipo de equipamento, com diferenciados tipos de martelos, e observou que uma das máquinas apresentava maior capacidade de processamento e menor consumo específico, em relação às demais, por causa da grande área livre das suas peneiras e do maior número de martelos, comparada com outras máquinas. Por isso, o autor conclui que o maior número de martelos resulta em maior número de golpes no grão, fazendo sua desintegração mais rápida.

Pozza et al. (2005), avaliando a moagem, a granulometria e o consumo de energia em moinhos de martelo, concluíram que a baixa taxa de moagem em uma das máquinas poderia ser reflexo da combinação entre a pequena área da peneira e o menor número de martelos, o que, consequentemente, proporcionou maior tempo e consumo de energia na moagem.

Zanotto et al. (1994), avaliando o efeito do grau de moagem no valor energético do milho para frangos de corte, utilizando peneiras de 2,5; 3,5; 4,5; e $10 \mathrm{~mm}$ de diâmetro dos furos, concluíram que o grau de moagem não influenciou no valor energético do milho, porém, ao aumentar o grau de moagem de 2,5 para $10 \mathrm{~mm}$, economizaram energia elétrica e tempo de moagem.

Zanotto et al. (1999) observaram, porém, que o consumo de energia elétrica reduziu-se em até $62 \%$, o rendimento de moagem aumentou em até $166 \%$ e o custo da ração farelada reduziu-se em até 0,309\%, em função de um maior DGM das partículas do milho $(515,655$ e $905 \mathrm{~mm})$, e que a variação na granulometria do milho, de 515 a $905 \mathrm{~mm}$, não influenciou o desempenho nem a mortalidade de frangos de corte.

Segundo Klinger (1995), a granulometria mais grosseira (peneiras de 8 e $12 \mathrm{~mm}$ ) pode ser utilizada desde o primeiro dia de idade, sem que o desempenho final dos frangos de corte seja afetado, além de representar considerável economia de energia e aumento no rendimento industrial da moagem. 
Em função do exposto, este trabalho teve como objetivo avaliar um modelo comercial de DPM, visando à melhoria da capacidade de produção e do consumo específico de energia na moagem do milho, realizando, para isto, alterações em parâmetros de seu funcionamento, bem como no próprio projeto original.

\section{MATERIAL E MÉTODOS}

O experimento foi conduzido no Laboratório de Mecanização Agrícola, do Departamento de Engenharia Agrícola (DEA), da Universidade Federal de Viçosa (UFV).

Utilizou-se o milho com $12 \%$ de umidade em base úmida, determinada após o processamento e homogeneização das amostras, que foram embaladas em filme plástico para evitar perda de umidade e, posteriormente, colocadas para secagem em estufa com ar quente circulante, com temperatura entre $65 \mathrm{e}$ $70{ }^{\circ} \mathrm{C}$, por um período aproximado de $72 \mathrm{~h}$.

$\mathrm{Na}$ Figura 1, apresentam-se as partes que compõem a máquina avaliada.

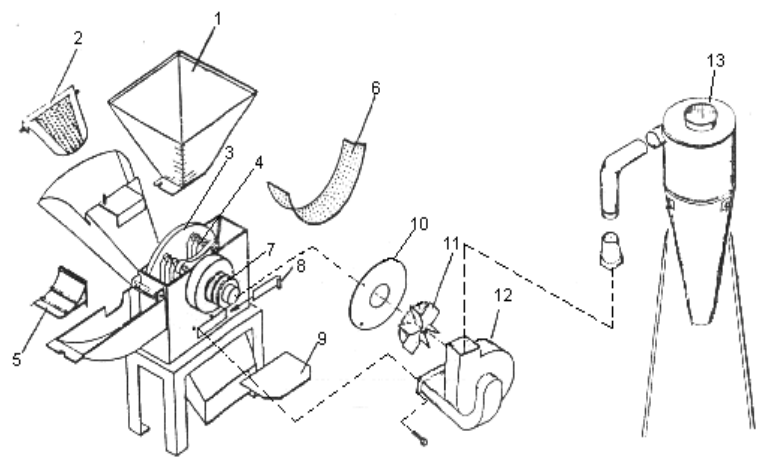

Figura 1. 1) moega de alimentação, 2) tampa da abertura de alimentação, 3) rotor, 4) martelos, 5) tampa da saída superior, 6) peneira, 7) polia para acionamento, 8) tampa para limpeza, 9) tampa inferior, 10; 11 e 12) componentes do transportador pneumático e 13) ciclone.
As principais características técnicas da máquina avaliada estão descritas no Quadro 1. As informações obtidas são oriundas do manual que acompanha a máquina.

Conforme o manual do fabricante, Quadro 1, existe uma variação nas unidades de potência nominal, rotação recomendada e capacidade de produção. Esta variação ocorre devido ao tipo de peneira utilizada, que influencia na potência, umidade do produto utilizado, entre outras.

Utilizaram-se quatro rotações (4000, 3757, 2931 e $2335 \mathrm{rpm}$ ); quatro variações do número de martelos (4, 5, 6 e 7 martelos por pino) e três peneiras de 3, 5 e $10 \mathrm{~mm}$ de diâmetro dos furos (Figura 2). A opção de avaliar rotações menores que a nominal, é devido ao fato da potência variar diretamente com esta variável, desta forma procurou-se diminuir a rotação e observar a influência desta no consumo específico de energia no processamento do milho. Já a variação do número de martelos foi realizada para observar a influência do número de martelos no consumo específico de energia, já que haverá variação no tamanho das partículas moídas que poderão influenciar no consumo específico de energia.

As rotações foram avaliadas de acordo com a faixa estipulada pelo fabricante, sendo a primeira a rotação nominal e as demais aquelas abaixo desta; que foram controladas por intermédio de um inversor de frequência VECTRUE INVERTER, modelo CFW 09/WEG.

Para alteração do número de martelos, foram torneados novos anéis que permitiram sua fixação nos pinos. Os anéis que prendiam os martelos na condição nominal, conforme Figura 2.b, foram substituídos por anéis maiores que estes, para o caso de 4 martelos e por anéis menores que estes, no caso de 6 e 7 martelos para que os mesmos pudessem se fixar nos eixos conforme pode ser observado na Figura 2.

Quadro 1. Características técnicas do DPM

\begin{tabular}{lc}
\hline \multicolumn{1}{c}{ Características } & Unidades \\
\hline Potência nominal & 3,7 a $5,5 \mathrm{~kW}(5,0 \mathrm{a} 7,5 \mathrm{cv})$ \\
Rotação recomendada & $4000 \mathrm{a} 4100 \mathrm{rpm} *$ \\
$\mathrm{~N}^{\circ}$ de martelos por pino & 5 \\
$\mathrm{~N}^{\mathrm{o}}$ total de martelos & 20 \\
Capacidade de produção (Peneira de $3 \mathrm{~mm})$ & $0,35 \mathrm{a} 0,55 \mathrm{t} \mathrm{h}^{-1}$ \\
Capacidade de produção (Peneira de $5 \mathrm{~mm})$ & 0,50 a $0,75 \mathrm{t} \mathrm{h}^{-1}$ \\
Capacidade de produção (Peneira de $10 \mathrm{~mm})$ & ------ \\
\hline
\end{tabular}



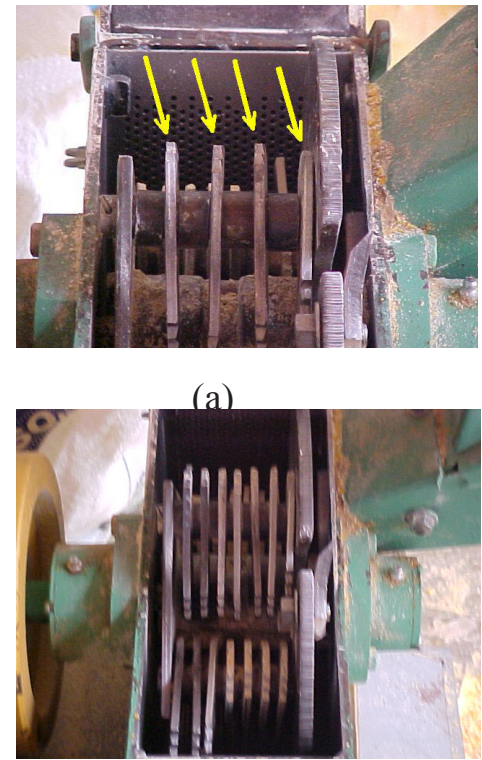

(d)

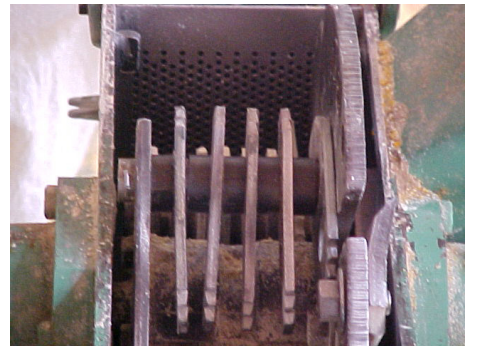

(b)

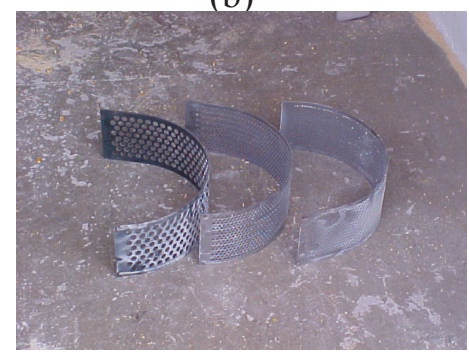

(e)

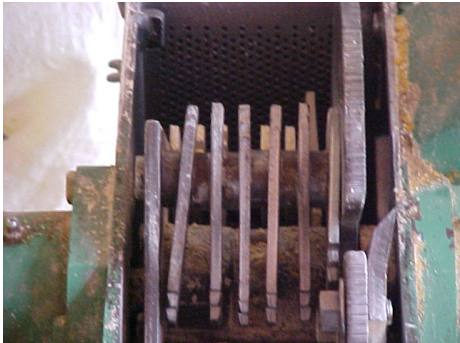

(c)

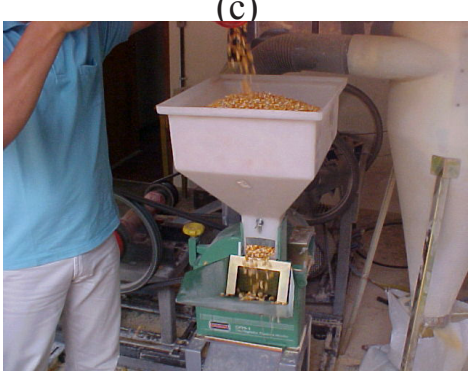

(f)

Figura 2. Configuração da máquina: (a) 4 martelos, (b) 5 martelos, (c) 6 martelos, (d) 7 martelos, (e) conjunto de peneiras e (f) processo de alimentação da máquina.

A bancada de ensaios, montada segundo Dias et al. (1998), é mostrada na Figura 3.

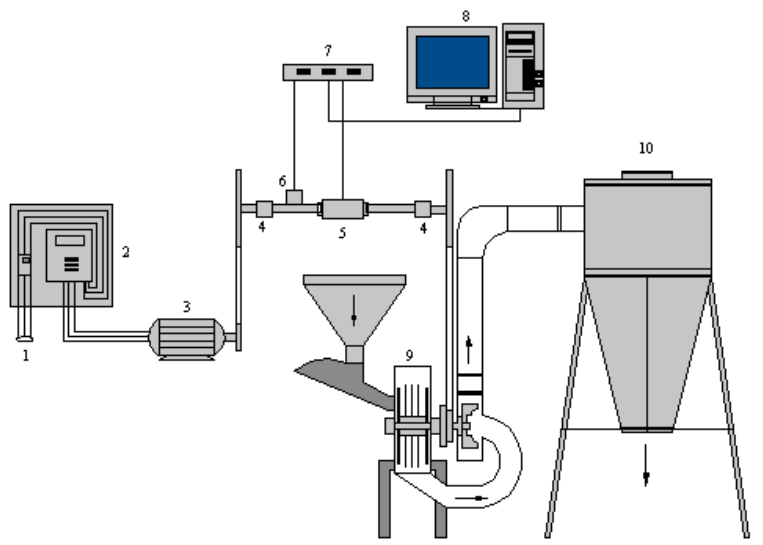

Figura 3. Bancada de ensaios: (1) Rede elétrica; (2) Inversor de freqüência; (3) Motor; (4) Mancais; (5) Torquímetro; (6) Sensor de rotação; (7) Aquisição de dados; (8) Computador; (9) DPM; (10) Ciclone.

\section{Capacidade de Produção}

Para avaliar a capacidade de produção, o equipamento foi colocado em funcionamento $\mathrm{e}$ a alimentação com milho foi feita pela moega de alimentação, mantida cheia durante todo o processo, para garantir que não houvesse interferência por variação de carga.

Após entrar em funcionamento, esperava-se o sistema atingir regime permanente e então começava- se a contar o tempo de processamento, iniciando simultaneamente a coleta do produto moído na saída do ciclone. Adotou-se, então, um tempo de coleta de cinco minutos. O farelo de milho resultante teve sua massa medida, em uma balança aferida, para avaliação da capacidade de produção da máquina.

A capacidade de produção foi determinada conforme equação 1 ,

$$
\mathrm{Cp}=\frac{\mathrm{m}}{\mathrm{t}}
$$

em que,

$$
\begin{aligned}
\mathrm{Cp} & =\text { capacidade de produção, } \mathrm{th}^{-1} ; \\
\mathrm{m} & =\text { massa do milho moído, } \mathrm{t} ; \\
\mathrm{t} & =\text { tempo de processamento, } \mathrm{h} .
\end{aligned}
$$

\section{Demanda de Potência}

Para determinar a potência, foram mensurados o torque e a rotação de operação das máquinas. $\mathrm{O}$ torque foi medido por um torquímetro da marca ÔMEGA ENGINEERING, INC, modelo TQ 501$2 \mathrm{k}$, a $6000 \mathrm{rpm}$, com capacidade de até $226 \mathrm{mN}$, erro de $0,18 \%$ de fundo de escala e taxa de saída de $2 \mathrm{mV} \mathrm{V}^{-1}$ nominal de alimentação, conforme Figura 4.1. A rotação foi medida com o auxílio de um sensor magnético com resolução de uma revolução, posicionado no eixo do torquímetro. 
Utilizou-se um sistema de aquisição de dados da HBM modelo "Spider 8", que utiliza o programa (software) "Catman v. 1.2" para seu controle, o qual possibilita a visualização gráfica instantânea dos dados.

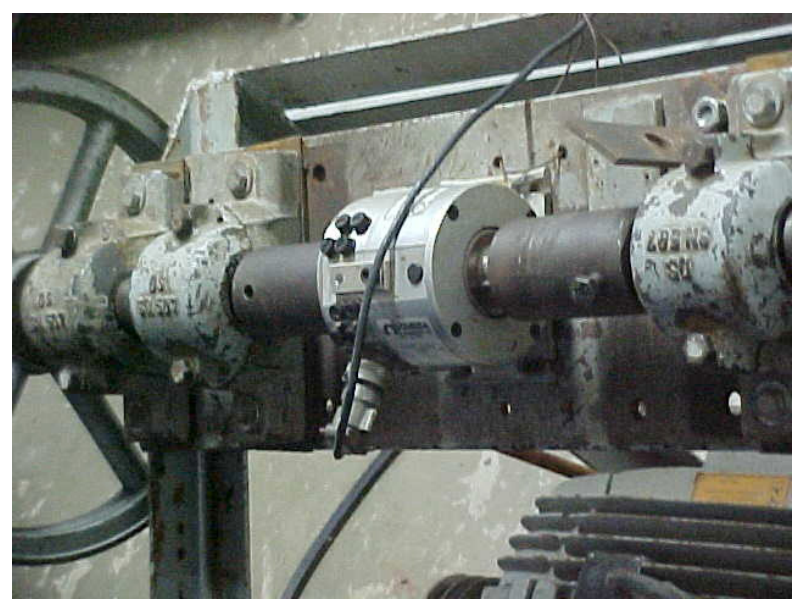

(1)

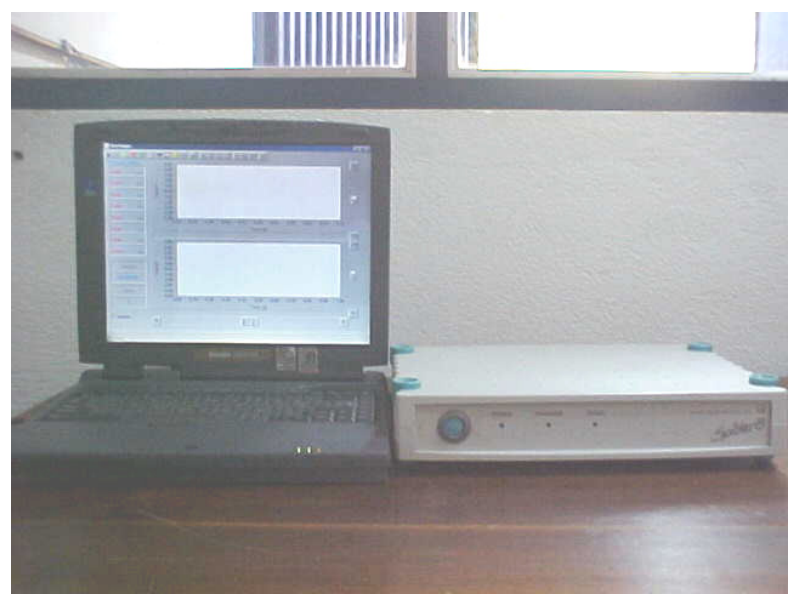

(2)

Figura 5. Histograma de medição do torque e rotação.

A potência demandada foi então determinada por intermédio da equação 2 ,

$$
P=T \times n \times k
$$

em que,

$$
\begin{aligned}
& \mathrm{P}=\text { potência demandada, } \mathrm{kW} \\
& \mathrm{T}=\text { torque, } \mathrm{mN} \\
& \mathrm{n}=\text { rotação, } \mathrm{rpm} ; \\
& \mathrm{k}=1,0472 \times 10^{-4}, \text { índice conversor de unidades. }
\end{aligned}
$$

\section{Consumo Específico de Energia}

$\mathrm{O}$ consumo específico de energia $\left(\mathrm{kWh} \mathrm{t}^{-1}\right)$ foi avaliado, relacionando-se a potência demandada com a capacidade de produção $\left(\mathrm{t} \mathrm{h}^{-1}\right)$, conforme equação 3 ,

$$
\mathrm{Ce}=\frac{P}{C p}
$$

em que,

$\mathrm{Ce}=$ consumo específico de energia, $\mathrm{kWh} \mathrm{t}^{-1}$;

$\mathrm{P}=$ potência demandada, $\mathrm{kW}$;

$\mathrm{Cp}=$ capacidade de produção, $\mathrm{th}^{-1}$.

\section{RESULTADOS E DISCUSSÃO}

\section{Capacidade de Produção}

Conforme mostra a Figura 6, na peneira de $3 \mathrm{~mm}$, o grupo de 5 martelos (condição nominal de fábrica) proporcionou menor capacidade de produção. Ao utilizar as peneiras de 5 e $10 \mathrm{~mm}$, a condição nominal também não apresentou capacidade de produção satisfatória, quando comparada aos demais números de martelos. Estes resultados corroboram aqueles encontrados por Rodrigues (2000) e Pozza et al. (2005), que concluíram que o maior número de martelos resulta em maior número de golpes no grão, fazendo sua desintegração mais rápida.

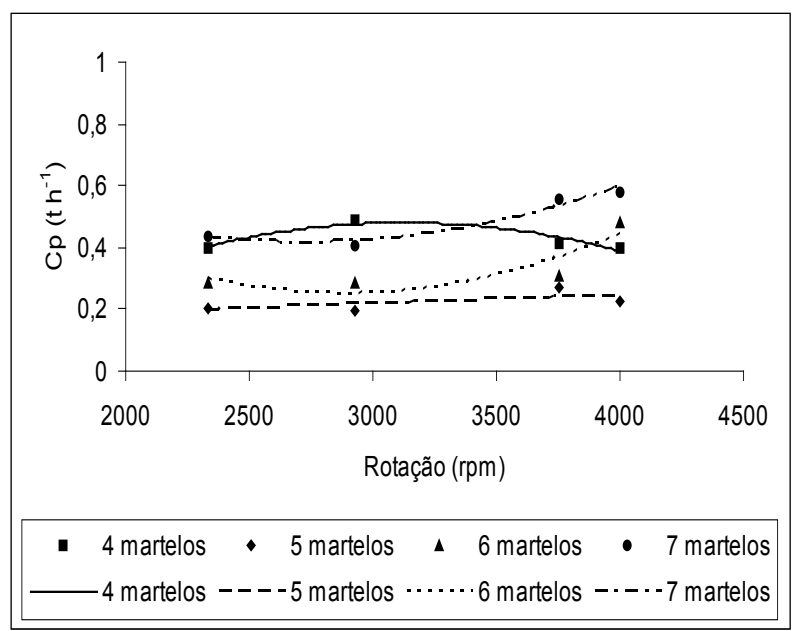

Figura 6. Capacidade de produção do DPM na peneira de $3 \mathrm{~mm}$.

Apesar de usar número menor de martelos do que o da condição nominal, valor bem satisfatório foi encontrado ao utilizar 4 martelos por pino, na peneira de $3 \mathrm{~mm}$, que também apresentou maior capacidade de produção do que o grupo de 5 martelos.

$\mathrm{Na}$ condição nominal de 5 martelos e $4000 \mathrm{rpm}$, 
a capacidade de produção apresenta valores abaixo daqueles indicados pelo fabricante, para a peneira de $3 \mathrm{~mm}$, de $0,22 \mathrm{t} \mathrm{h}^{-1}$, e valores coerentes com o apresentado pelo fabricante, de $0,51 \mathrm{t} \mathrm{h}^{-1}$, para a peneira de $5 \mathrm{~mm}$. Como o fabricante não disponibiliza dados de capacidade de produção da peneira de 10 mm, não foi possível fazer a comparação, mas o valor encontrado foi de $0,48 \mathrm{th}^{-1}$, inferior ao da peneira de $5 \mathrm{~mm}$ (Figura 7). Nesta condição nominal de número de martelos, observa-se que a peneira de $3 \mathrm{~mm}$ foi a que apresentou menor capacidade de produção.

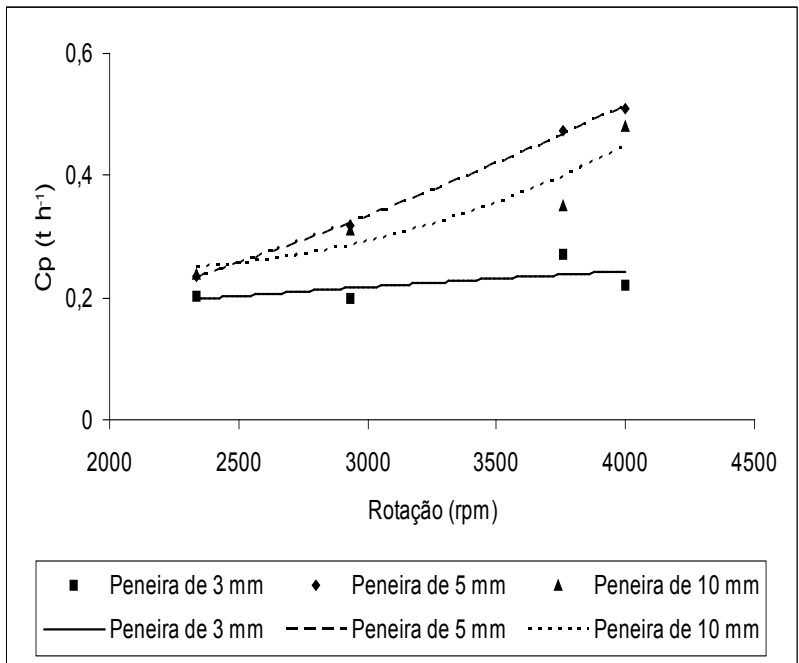

Figura 7. Capacidade de produção do DPM na condição de 5 martelos por pino.

Por isso, a baixa capacidade de produção da peneira de $3 \mathrm{~mm}$ pode ser reflexo de sua pequena área, conforme encontrado por Pozza et al. (2005).

\section{Potência}

Para a potência (Figura 8), o grupo de 7 martelos por pino demandou maior valor, seguido pelos grupos de 4, 6 e 5 martelos, devido ao fato de ter apresentado maior capacidade de produção. Pode-se observar, ainda, que, à medida que a rotação aumenta, há um acréscimo da potência demandada.

De acordo com a Figura 9, na condição de 7 martelos por pino, observa-se maior potência na peneira de $3 \mathrm{~mm}$; condição esta também observada nos demais conjuntos de número de martelos. Valor este esperado, pois quanto menor o diâmetro da peneira, maior é a dificuldade para que o produto passe por seus crivos, demandando maior potência.
Todas as combinações de martelos, rotações e peneiras proporcionaram potência, no intervalo estipulado pelo fabricante, de 3,7 a $5,5 \mathrm{~kW}$, com exceção da combinação peneira de $3 \mathrm{~mm}$ e 7 martelos por pino, que, mesmo acima do intervalo, está muito próximo desse com 5,7 $\mathrm{kW}$. Desta forma, os valores estipulados pelo fabricante são coerentes com os encontrados.

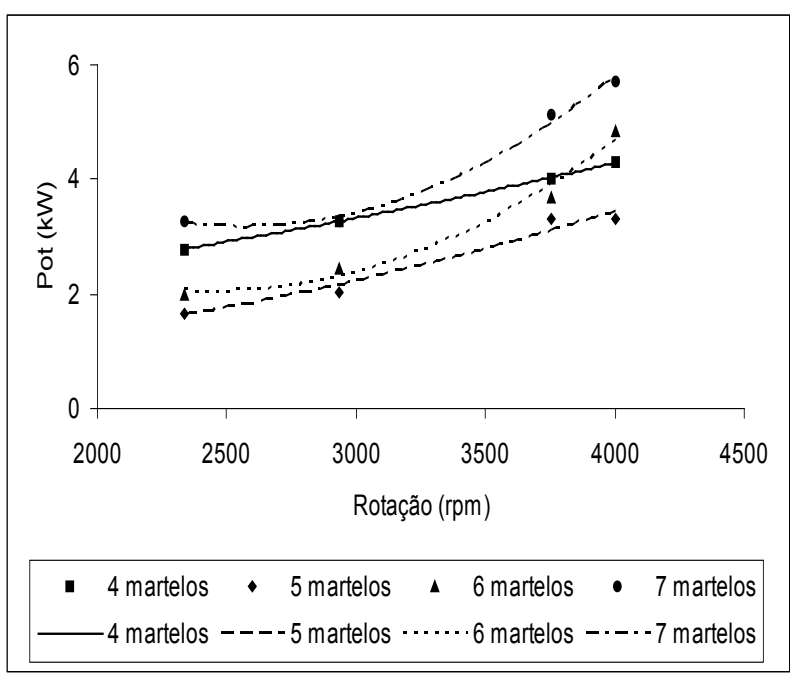

Figura 8. Potência do DPM na peneira de $3 \mathrm{~mm}$.

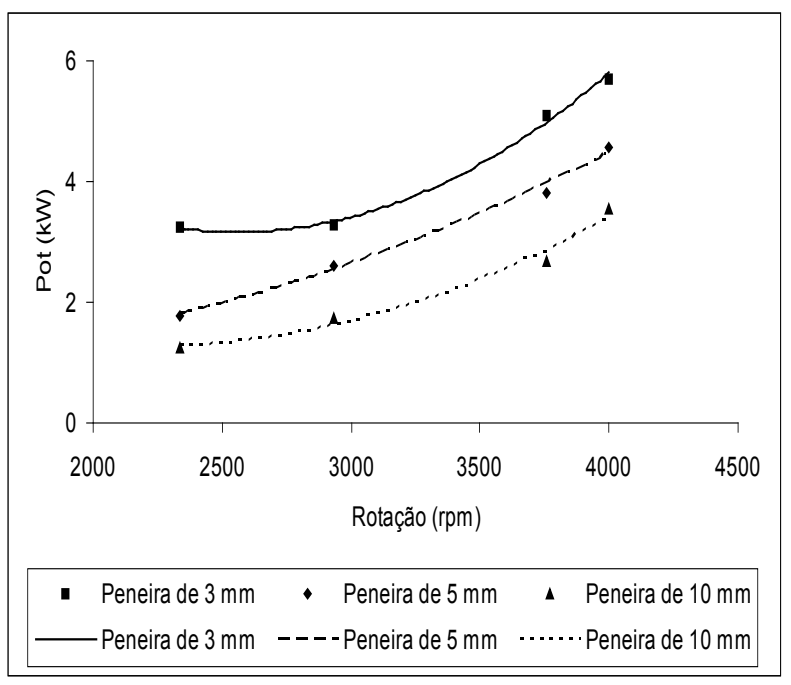

Figura 9. Potência do DPM na condição de 7 martelos por pino.

\section{Consumo Específico}

Conforme mostra a figura 10, observase, na condição de 7 martelos por pino, que maior consumo específico foi proporcionado pela peneira de $3 \mathrm{~mm}$, condição esta também encontrada nos demais martelos. 


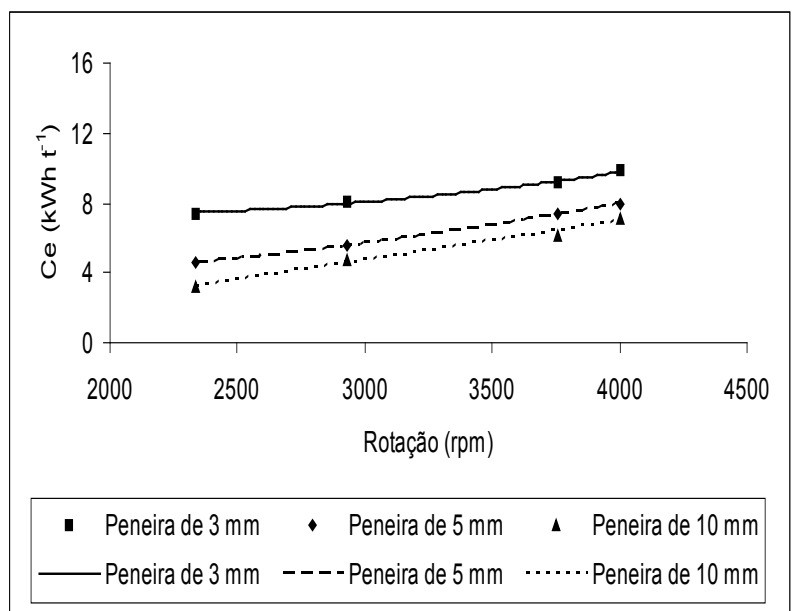

Figura 10. Consumo específico do DPM na condição de 7 martelos por pino.

Resultados semelhantes foram encontrados por Rodrigues (2000), Zanotto et al. (1994), Zanotto et al. (1999) e Klinger (1995). Essa peneira proporciona maior consumo específico, por exigir que os grãos sejam reduzidos a partículas bem menores que aquelas processadas pelas demais.

Considerando o consumo específico de energia de acordo com o número de martelos, ao utilizar a peneira de $3 \mathrm{~mm}$, recomenda-se o uso de 7 martelos por pino, para que o milho seja triturado em partículas menores a fim de ultrapassar os crivos dessa peneira com maior facilidade (Figura 11). Nas peneiras de 5 e $10 \mathrm{~mm}$, há uma indefinição quanto aos valores de número de martelos.

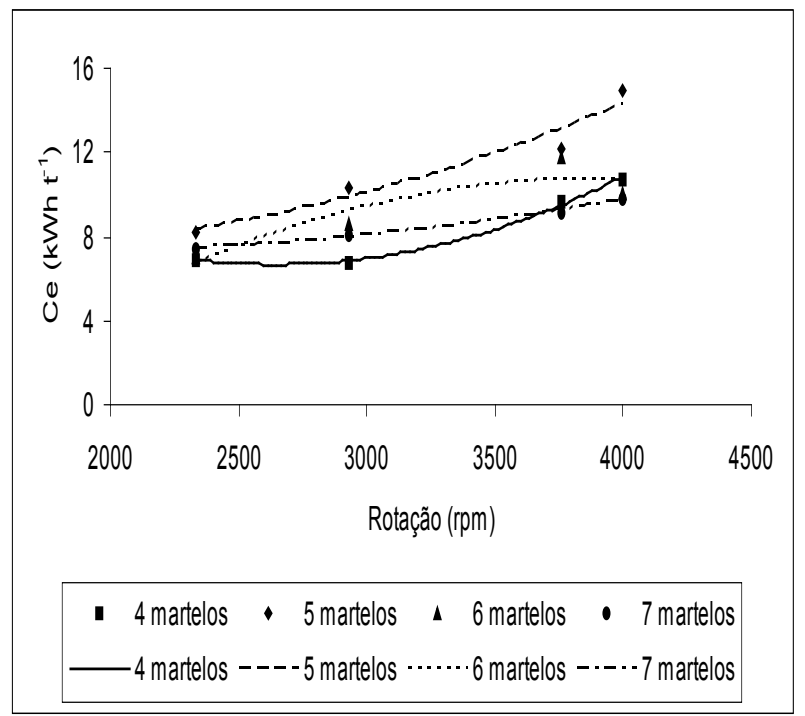

Figura 11. Consumo específico do DPM na peneira de $3 \mathrm{~mm}$.

Na rotação e número de martelos nominais, ou seja, 4000 rpm e 5 martelos por pino, os seguintes valores foram encontrados:
- peneira de $3 \mathrm{~mm}: 0,22 \mathrm{t} \mathrm{h}^{-1}$, demandando um consumo específico de $14,9 \mathrm{kWh} \mathrm{t}^{-1}$. Valores superiores de capacidade de produção com menor consumo específico de energia foram alcançados ao se utilizarem 4, 6 e 7 martelos por pino. Ao se utilizarem 7 martelos, foi possível processar $0,58 \mathrm{t} \mathrm{h}^{-1}$, demandando $9,8 \mathrm{kWh} \mathrm{t}^{-1}$ nessa peneira;

- peneira de $5 \mathrm{~mm}: 0,51 \mathrm{t} \mathrm{h}^{-1}$, demandando um consumo específico de $7,9 \mathrm{kWh} \mathrm{t}^{-1}$. Valores mais eficientes foram alcançados ao se utilizarem 6 martelos, com $0,53 \mathrm{t} \mathrm{h}^{-1}$ e $7,8 \mathrm{kWh} \mathrm{t}^{-1}$;

- peneira de $10 \mathrm{~mm}: 0,48 \mathrm{t} \mathrm{h}^{-1}$, demandando um consumo específico de 7,0 $\mathrm{kWh} \mathrm{t}^{-1}$. Neste caso, os outros martelos não apresentaram resultados melhores, não justificando a troca do número de martelos.

Existe a possibilidade de redução da demanda energética do equipamento, diminuindo-se a rotação, porém, a capacidade de produção fica limitada. O desejável seria a identificação de alterações no projeto da máquina que permitissem reduzir a rotação, visando a diminuir o consumo específico sem comprometer a capacidade de produção. Uma opção poderia ser aumentar o número de martelos, pois a redução do tamanho das partículas do material processado depende do número de impactos que o material recebe.

$\mathrm{O}$ aumento da área perfurada da peneira é outra possibilidade, entretanto, este procedimento pode reduzir a vida útil da peneira, por causa de sua menor resistência ao desgaste.

A utilização da peneira de maior diâmetro pode ser uma opção, que dependeria também da aceitação da ração por cada tipo de animal. Zanotto et al. (1994) concluíram que o grau de moagem não influenciou no valor energético do milho, para frangos de corte; Zanotto et al. (1999) observaram que o custo da ração farelada reduziu-se, com o maior diâmetro das partículas do milho triturado, e que a variação na granulometria do milho, de 515 a $905 \mathrm{~mm}$, não influenciou o desempenho nem a mortalidade de frangos de corte. Klinger (1995) concluiu que a granulometria mais grosseira poderia ser utilizada desde o primeiro dia de idade, sem que o desempenho final dos frangos de corte pudesse ser afetado, além de representar considerável economia de energia e aumento no rendimento industrial da moagem. 
CONCLUSÕES

- Foi possível obter melhor demanda energética, neste experimento, alterando-se o número de martelos da máquina.

- A potência demandada está dentro do indicado pelo fabricante, porém, existe a possibilidade de menor demanda, utilizando-se menores rotações.

- A peneira de $3 \mathrm{~mm}$ foi a que demandou maior potência.

- Há a necessidade de alterações no projeto da máquina que permitam reduzir a rotação dos martelos, visando a diminuir o consumo específico, sem, contudo, comprometer a capacidade de produção.

- A utilização da peneira de maior diâmetro é uma opção na moagem da ração, para diminuição da demanda energética.

\section{REFERÊNCIAS BIBLIOGRÁFICAS}

DIAS, G.P.; VITÓRIA, E.L.; REIS, E.F.; KHOURY JÚNIOR, J.K. Bancada de testes de equipamentos eletrorrurais. In: CONGRESSO LATINO AMERICANO DE DISTRIBUIÇÃO DE ENERGIA ELÉTRICA, 3, 1998, São Paulo. Anais... São Paulo: EPUSP/IEEE, 1998. p.669

KLINGER, C.M. Efeito da granulometria do milho e forma de ração no desempenho de frango de corte. Viçosa: UFV, 1995. 78p. (Dissertação de Mestrado)

MARTIN, S. Particle size reduction. In: NFIA - feed manufacturing short course. Kansas: Kansas State University, 1988. 10p.

MINISTÉRIO DE MINAS E ENERGIA. Implementação da lei de eficiência energética -
Comitê gestor de indicadores e níveis de eficiência energética-CGIEE. Brasília, MME, 2002. 87p.

PEREIRA, S.; DIAS, G.P.; OLIVEIRA FILHO, D.; SOUZA, L.C.V. Metodologia para avaliação de desempenho e produção específica de picadoras e ensiladoras de forragem. In: PRIMEIRO SEMINÁRIO ENERGIA NA AGRICULTURA, 1, 2000, Uberaba. Anais... Uberaba: CEMIG, 2000. p.3-41.

POZZA, P.C.; POZZA, M.S.S.; RICHARD, S.; OLIVEIRA, F.G.; GASPAROTTO, E.S.; SCHLICKMANN, F. Avaliação da moagem e granulometria do milho e consumo de energia no processamento em moinhos de martelos. Ciência Rural, v.35, n.1, p.235-238, 2005.

RODRIGUES, D.E. Avaliação do desempenho de cinco marcas de Desintegrador/Picador/Moedor (DPM) na moagem do milho. Viçosa: UFV, 2000. 51p. (Dissertação de Mestrado)

ZANOTTO, D.L., ALBINO, L.F.T., BRUM, P.A.R. Efeito do grau de moagem no valor energético do milho para frangos de corte. In: REUNIÃO ANUAL DA SOCIEDADE BRASILEIRA DE ZOOTECNIA, 31, 1994, Maringá. Anais... Maringá: SBZ, 1994. p.57

ZANOTTO, D. L.; GUIDONO, A.L.; ALBINO, L.F.T.; BRUM, P.R.; FIALHO, F.B. Efeito da granulometria sobre o conteúdo energético do milho para frangos de corte. Concórdia: EMBRAPA, CNPSA, 1998. 2p

ZANOTTO, D.L., GUIDONI, A.L., BRUM, P.R. Granulometria do milho em rações fareladas para frangos de corte. In: REUNIÃO ANUAL DA SOCIEDADE BRASILEIRA DE ZOOTECNIA, 36, 1999, Porto Alegre. Anais... Porto Alegre: SBZ, 1999. p.27 